\title{
O pensamento como criação: Filosofia, Arte e Ciência. O desafio de Deleuze e Guattari *
}

\author{
CATARINA POMBO NABAIS **
}

\begin{abstract}
In their last four-handed book, Qu'est ce que la Philosophie?, Deleuze and Guattari support the thesis that philosophy, science and art constitute three different dimensions of thought. Different but complementary. Among them there is no hierarchy or dependency. Deleuze and Guattari state it clearly: "The three ways are specific, as straightforward as each other, and are distinguished by the nature of the plan and what occupies it. To think is to think by concepts, or by functions, or by sensations, and either of these thoughts is no better than the other, or more fully, more completely,

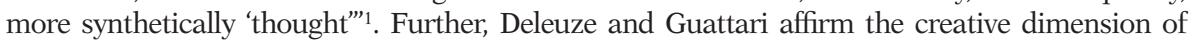
thought. "The act of thinking (...) is the only true creation"2. Science, art and philosophy thus have in common the fact that they are three creative forms of thought. Now, this article aims at clarifying the meaning of this thesis and at critically proposing an enlargement of its field of application, namely as a way of enlarging the scope and the metaphysical basis of the so-called area of Sci-Art. So, we will try to elucidate the relations between art, science and philosophy thought out by Deleuze and Guattari by gathering a series of concepts (such as "thought", "chaos", "virtual", "becoming", "infinite"). Moreover, we will critically point out the existence of a fundamental ambiguity concerning the status which Deleuze and Guattari end up by granting to philosophy in its relation to science and art. Finally, we will stress the need of enlarging to science and art the transversality attributed by Deleuze and Guattari to philosophy and we will call for another concept ("intercessors") so that the relationship between science, art and philosophy can be more deeply though out.
\end{abstract}

Keywords: art, chaos, philosophy, science, thought.

\section{Introdução}

A

s ciências e as artes foram sempre actividades muito próximas, com desenvolvimentos muitas vezes paralelos, com relações subterrâneas e profundas. No entanto, apesar do enorme número

* Este trabalho é financiado por fundos nacionais através da FCT - Fundação para a Ciência e a Tecnologia, I.P., no âmbito da Norma Transitória - DL57/2016/CP1479/ CT0067 e da Norma Transitória - DL57/2016/CP1479/CT0065.

** Faculdade de Ciências da Universidade de Lisboa, Departamento de História e Filosofia das Ciências.

$\triangle$ ccnabais@fc.ul.pt

1. Gilles Deleuze e Félix Guattari, Qu'est-ce que la Philosophie? (Paris : Minuit, 1991), 187.

2. Gilles Deleuze, Proust et les Signes (Paris : PUF, 1987), 118-9. 
de tentativas, nunca foi possível descobrir e entender completamente as forças veladas, as conexões secretas, as proximidades múltiplas que atravessam essas duas magníficas atividades humanas que são a "Ciência" e a "Arte".

É neste contexto que assistimos hoje à constituição de uma nova, ampla e florescente área de pesquisa denominada "Ciência e Arte", ou "Ciência-Arte", ou simplesmente Sci-Art. Poderia parecer que ela vinha finalmente ocupar-se, de forma sistemática, da problematização e esclarecimento das relações entre ciência e arte, do questionamento dos pontos comuns, das intersecções e das diferenças entre as duas actividades, tarefa que, até aqui, tem cabido sobretudo a filósofos e a historiadores da ciência. Não é, porém, isso que acontece. Em termos de produção teórica, a nova área tem sobretudo dado origem a estudos orientados para a descrição e análise dos inúmeros e diversificados casos de confluência entre cientistas e artistas que hoje se verificam (estudos de caso). São sobretudo apresentações de experiências pelos próprios que as realizaram (como no caso da artista portuguesa Marta de Menezes que, em laboratório, introduziu uma alteração genética na asa de uma borboleta, experiencia que foi publicada na revista Nature e ficou célebre pela sua novidade e mestria da sua realização ${ }^{3}$ ), análises críticas sobre determinados trabalhos ou, em número reduzido, obras de conjunto que procuram oferecer uma panorâmica, mais ou menos alargada, do que se faz em Sci-Art ${ }^{4}$.

A nova área tem de facto uma dimensão sobretudo prática. Os praticantes de "Ciência e Arte" são, por um lado, artistas apaixonados pela ciência, isto é, artistas que se aproximaram decisivamente da actividade científica, que deslocaram os seus ateliers para os laboratórios dos cientistas, que aí procuram aprender, e aplicar livremente, metodologias, instrumentos, tecnologias, procedimentos típicos da prática científica (vejam-se apenas dois casos desenvolvidos em Portugal: Rob Kessler ${ }^{5}$, artista inglês que foi residente no "Instituto Gulbenkian de Ciência" (IGC) em Lisboa, e Hervig Turk ${ }^{6}$, artista austríaco que foi residente no "Instituto

3. Marta de Menezes <https://martademenezes.com/portfolio/projects/>.

4. É o caso do belíssimo livro de Martin Kemp, Visualizatios. The Nature Book of Art and Science (Oxford/New York: Oxford University Press, 2000) e, entre nós, do volume Inside. Arte e Ciência, editado por Leonel Moura (Lisboa: LxXL, 2009) e que constitui o catálogo de uma exposição, com o mesmo título, realizada na Cordoaria Nacional, em Lisboa, em 2009.

5. Rob Kessler <https://www.robkesseler.co.uk/>.

6. Hervig Turk <https://anti-utopias.com/artist/herwig-turk/>. 
da Medicina Molecular" (IMM) e no "Instituto de Imagens Biomédicas e Ciências da Vida" (IBILI) da Universidade de Coimbra; por outro lado, cientistas profundamente interessados em arte (veja-se o caso do português de Pedro Salgado ${ }^{7}$, biólogo que se tornou referência internacional em ilustração científica, nomeadamente, de algumas espécies de peixes), cientistas que recebem artistas nos seus espaços de trabalho, ou porque são sensíveis às virtualidades criativas que o contacto directo com as práticas artistas lhes podem trazer, ou porque - e, estes, em menor número - esperam poder aprender com as suas obras (como no caso de Lucy Lyons que, desenhando sobretudo doenças de pele, conseguiu compreender de uma forma tão profunda essas mesmas doenças que muitos dermatologistas passaram a usar os seus desenhos como ferramenta no estudo da pele ${ }^{8}$.

Neste contexto, pensamos que a área "Ciência e Arte", que tem estado polarizada em duas perspectivas diferentes - o ponto de vista da ciência e o ponto de vista da arte - deve ser enriquecida com a contributo da filosofia. O domínio dual da "Ciência e Arte" deve alargar-se, pela introdução de um terceiro elemento - a filosofia - num campo interdisciplinar triádico: "Ciência-Arte-Filosofia". Existem razões efectivas, estruturas metafísicas imanentes e condições constitutivas de cada um destes três domínios, que justificam essa triangulação.

Este artigo pretende, antes de mais, sugerir esse alargamento. Não se trata de defender que aquilo a que se chama "Ciência e Arte" é, em si mesmo, um tópico filosófico, ou seja, que é à filosofia que cabe pensar as outras duas atividades. Como se a filosofia tivesse o exclusivo do pensamento. Como se, só ela tivesse condições para pensar essas relações. O nosso ponto de partida é outro: para se perceberem as relações entre ciência e arte, há que pensar essas relações no interior da sua triangulação com a filosofia. Como defenderemos, as três formas de pensamento relacionam-se de forma imanente, isto é, há uma ontologia que subjaz à sua própria relação. $\mathrm{O}$ estabelecimento das relações entre as três disciplinas não é resultado de uma vontade subjectiva de relacionar arte, ciência e filosofia. Há estruturas constitutivas que justificam as relações entre si das três disciplinas. É justamente nessa base que nos parece legítimo propor

7. Pedro Salgado, <https://www.fc.up.pt/Ilustracao_Cientifica/corpo-docente/pedrosalgado/>. Cf. também Pedro Salgado, "Field sketching and scientific illustration: drawing to understand nature and drawing to explain" in Image in science and art, editado por Olga Pombo, 221-231 (Lisboa : Fim de Século, 2017).

8. Lucy Lyons <https://www.lucylyons.org/>. 
que a relação dual que, em geral, se estabelece entre "Ciência e Arte" (SciArt) seja alargada pela introdução da filosofia, dando-se assim origem a um campo interdisciplinar triádico: "Ciência-Arte-Filosofia" .

Entre os filósofos contemporâneos, Gilles Deleuze é amplamente reconhecido como o pensador da tripla relação entre filosofia, ciência e arte. No seu último livro, escrito conjuntamente com Félix Guattari, Qu'est-ce que la Philosophie? (1991), é desenhada uma nova cartografia do pensamento na qual filosofia, ciência e arte são consideradas as três dimensões criativas do pensamento, correspondendo respetivamente à criação de conceitos (filosofia), de funções (ciência) e de afectos / sensações (arte). Diferentes, mas complementares. Entre elas não há hierarquia nem dependência. Deleuze e Guattari afirmam-no claramente: “As três vias são específicas, tão diretas umas como as outras, e distinguem-se pela natureza do plano e daquilo que o ocupa. Pensar, é pensar por conceitos, ou então por funções, ou então por sensações, e qualquer um destes pensamentos não é melhor do que o outro, ou mais plenamente, mais completamente, mais sinteticamente 'pensamento"' 10.

Esta será, pois, a nossa referência fundamental. O propósito deste artigo é justamente contribuir para a compreensão critica destas teses de Deleuze e Guattari sobre a relação entre ciência, arte e filosofia procurando ver de que modo elas podem ser enriquecidas, alargadas, desenvolvidas. O desafio que nos fica colocado é o de saber: em que medida ciência, arte e filosofia são formas do pensamento? Em que consiste o seu comum caracter criativo? Quais os conceitos que é necessário convocar para dar conta da metafisica que subjaz à sua complementaridade? De que modo será possível desenvolver projectos inspirados na tríade ciência, arte e filosofia?

9. É este o projecto teórico que está na base do Laboratório de Ciência, Arte e Filosofia, ou SAP-LAB (Science.Art. Philosophy Lab) que tive a oportunidade de criar no Centro de Filosofia da Ciência da Universidade de Lisboa (CFCUL) em 2014 e que, desde então, tenho coordenado. O SapLab reúne investigadores de Ciência, Arte e Filosofia, assumindo-se como um espaço de pesquisa transversal e interdisciplinar cujas actividades (residências de artistas, filósofos e cientistas; workshops, conferencias, publicações, etc) visam promover o encontro e a fecundação reciproca entre estas três ordens disciplinares. Para informações mais detalhadas, cf. <http://sap-lab.org/>

10. Gilles Deleuze e Félix Guattari, Qu'est-ce que la Philosophie? (Paris: Minuit, 1991), 187 (nossa tradução). 


\section{Pensamento e caos: um modelo intensivo e intempestivo}

Para Deleuze, o pensamento não é uma reflexão que consistiria no movimento voluntário de procurar o sentido desvelado das coisas. O pensamento também não é uma atividade passiva, inerte, de paz com o mundo, como se fosse o registo do mundo e das suas paixões. Pelo contrário, para Deleuze, todo o pensamento é involuntário, não decorre de um movimento natural de pensar, de uma curiosidade espontânea ou capacidade de interrogação inata. $\mathrm{O}$ pensamento tem origem numa violência. Pensar é sofrer a ação de forças externas, do fora do pensamento. Pensar é o resultado de um encontro fortuito com elementos exteriores ao pensamento. Por isso, Deleuze, pode escrever: "O que é primeiro no pensamento é o arrombamento, a violência, é o inimigo, e nada supõe a filosofia, tudo parte de uma misosofia. Não contemos com o pensamento para fundar a necessidade relativa do que ele pensa; contemos, ao contrário, com a contingência de um encontro com aquilo que força a pensar, a fim de elevar e instalar a necessidade absoluta de um acto de pensar, de uma paixão de pensar"11.

Mas, para Deleuze, o pensamento tem também a forma do inesperado, do novo, daquilo que desafia em nós forças insuspeitadas. "Pensar é experimentar, mas a experimentação é sempre o que se está a fazer - o novo, o notável, o interessante que substituem a aparência da verdade e que são mais exigentes do que ela"12. Pensar é criar o novo. É abertura ao desconhecido, à terra incógnita para lá de toda o reconhecimento. "O próprio do novo, isto é, a diferença, é solicitar no pensamento forças que não são as do reconhecimento, nem hoje nem amanhã, potências de um outro modelo, numa terra incognita nunca reconhecida ou reconhecível" ${ }^{13}$. Quer dizer, quando posiciona o pensamento como resultado de uma génese violenta, Deleuze está, ao mesmo tempo, a afirmar uma dimensão activa e criativa do pensamento. Como escreve em Proust et les signes: "O acto de pensar não decorre de uma simples possibilidade natural; ele é, ao contrário, a única criação verdadeira. A criação é a gênese do acto de

11. Gilles Deleuze, Différence et Répétition (Paris : PUF, 1969), 181-2.

12. Gilles Deleuze e Félix Guattari, Qu'est-ce que la Philosophie?, 106. Mais adiante, Deleuze afirma mesmo: "Há tanto de experimentação como experiência de pensamento em filosofia como em ciência, e nos dois casos a experiência pode ser avassaladora, estando próxima do caos. Mas também há tanto de criação na ciência como na filosofia ou nas artes. Nenhuma criação existe sem experiência" (Gilles Deleuze e Félix Guattari, Qu'est-ce que la Philosophie?, 121).

13. Gilles Deleuze, Différence et Répétition, 177.

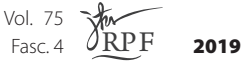


pensar no próprio pensamento"14. O pensamento é um acto de criação. É nele mesmo intempestivo, heterogéneo, modular e modulante da realidade à sua volta.

Daqui decorre que, para Deleuze, ciência, arte e filosofia sejam três formas de pensamento criativo. Isto é "há tanto de criação em ciência, como na filosofia ou nas artes"15. Estamos perante uma tese inaugural. Se é unanimemente reconhecido que a arte é o lugar por excelência da criação, já a ciência parece ser o lugar, mais da descoberta (ou até da invenção), do que da criação. Ora, Deleuze vem afirmar o carácter igualmente criativo da ciência, da arte e da filosofia. Como escreve: "Não podemos objectar que a criação se diz só do sensível e das artes, porque tanto a arte faz existir entidades espirituais como os conceitos filosóficos são também 'sensibilia'. Na verdade, as ciências, as artes e as filosofias são igualmente criadores, sendo que só a filosofia é a criadora de conceitos no sentido estrito" 16 .

Para percebermos melhor o que Deleuze e Guattari entendem por pensamento e pela forma como se processa o pensamento, é necessário olhar para um outro conceito, que Deleuze e Guattari designam de caos. Como defendem, todo o pensamento é relação com o caos. O pensamento é o resultado de uma operação que se faz ao caos, um corte do caos, é a própria composição do caos. Pensar, é dar consistência ao caos. Estamos perante uma definição intempestiva do pensamento. Contra a ideia clássica de pensamento como revelação, desvelamento, de um mundo ideal de ideias, contra a ideia moderna de pensamento como instância universal e homogénea, Deleuze vê o pensamento como um processo involuntário, intensivo e heterogéneo de diferenciação de uma virtualidade caótica. Mas, em que medida o pensamento se forma no e com o caos? O que é o caos?

Deleuze e Guattari definem o caos como um virtual que, enquanto velocidade absoluta, é nascimento e esvaziamento de todas as formas possíveis. "Definimos o caos menos pela sua desordem do que pela velocidade infinita com que se dissipa toda a forma que nele se esboça. É um vazio que não é um nada, mas um virtual, contendo todas as partículas possíveis e adquirindo todas as formas possíveis que surgem para, de imediato, desaparecerem, sem consistência nem referência, sem conse-

14. Gilles Deleuze, Proust et les Signes (Paris : PUF, 1987), 118-9.

15. Gilles Deleuze e Félix Guattari, Qu'est-ce que la Philosophie?, 121.

16. Gilles Deleuze e Félix Guattari, Qu'est-ce que la Philosophie?, 10-1. 
quência" ${ }^{17}$. Ou seja, o caos não é o nada, mas um campo virtual que contém todas as formas possíveis de pensamento. No entanto, o caos caracteriza-se também como sendo palco de permanente actualização e dissipação dessas formas. Como escrevem Deleuze e Guattari: "O que caracteriza o caos, de facto, é menos a ausência de determinações do que a velocidade infinita com que elas se esboçam e se dissipam: não é um movimento de uma para a outra, mas, pelo contrário, a impossibilidade de uma relação entre duas determinações, uma vez que uma não aparece sem que a outra já tenha desaparecido, e que uma aparece como dissipando-se quando a outra desaparece como um esboço" ${ }^{18}$. O caos é um fluxo incessante de determinações de todos os tipos, perceptivas, afectivas, intelectuais, que partilham o facto de serem aleatórias e de surgirem e desaparecerem à velocidade infinita.

Neste sentido, é importante sublinhar a dimensão virtual do caos. De uma forma muito esquemática, podemos dizer que a virtualidade do caos é a sua dimensão de sobrevoo do pensamento, uma dimensão de infinito que paira sobre o pensamento. Segundo Deleuze e Guattari, esta pregnância do virtual explica-se pela consciência do perigo e do vazio que o caos representa para o pensamento. Ao caracterizar o caos como virtual, Deleuze e Guattari salvam a dimensão construtiva imanente, criativa, do pensamento. Como fluxo incessante entre o virtual e o actual, o caos tem como que duas velocidades: uma velocidade do actual, como fundo sombrio, um sem-fundo onde tudo se dissolve como ponto de catástrofe (delírio absoluto); e uma velocidade do virtual, infinito, no qual o pensamento mergulha para dele extrair conceitos (filosofia), afectos (arte) e funções (ciência). Dito de outro modo: se o caos fosse apenas actual, o pensamento perder-se-ia no delírio, na alucinação, no abismo da desordem e da não-criação, do não-pensamento. Como explicam Deleuze e Guattari "o caos não é um estado inerte ou estacionário, não é uma mistura ao acaso. O caos caotiza, e desfaz, no infinito, toda a consistência” ${ }^{19}$.

17. Gilles Deleuze e Félix Guattari, Qu'est-ce que la Philosophie?, 111.

18. Gilles Deleuze e Félix Guattari, Qu'est-ce que la Philosophie ?, 44-45.

19. Gilles Deleuze e Félix Guattari, Qu'est-ce que la Philosophie ?, 45. Zourabichvili esclarece este ponto da seguinte forma: "Levantemos um equívoco: não poderia haver experiência de caos, pois seria confundida com o colapso do pensamento o qual se deixaria agarrar por ele sem encontrar alguns esquemas para se opor a ele, nem ter a intuição de um plano que viesse recortá-lo e que permitiria criar consistência (...). A experiência "real" começa com o corte ou a introdução de um plano. O caos, desde então, é mais pensado do que dado: ele é virtual" [François Zourabichvili, Le Vocabulaire de Deleuze (Paris: Ellipses, 2003), 60]. 
Também a diferença entre actual e virtual, que está na base do conceito de caos, é fundamental para se perceber o processo do devir. De facto, segundo Deleuze, o caos é o elemento de um programa ontológico sustentado na dupla virtual-actual, isto é, no processo de virtualização-actualização como condição de efetividade do ser e do pensamento. No lugar de uma teoria da transcendência, em que o ser é o resultado da actualização de uma essência ideal, Deleuze defende o actual como um processo singular de diferenciação. A seu ver, em toda a actualização, há mudança, há devir, e todo esse processo é de efetivação do virtual que se actualiza, que muda de natureza. O virtual é o campo intensivo, a energia vitalista, o "élan vital" que funciona no processo de individuação, de formação, de modulação do actual. Portanto, ao ser virtual, o caos designa precisamente este jogo, este campo dinâmico entre actualidade e virtualidade. Como linha de diferenciação, o caos faz parte da matéria do próprio pensamento, seja na criação de conceitos (filosofia), seja na criação de afectos (arte), seja na criação de funções (ciência). Ora, como consequência do caos enquanto campo dinâmico do devir, Deleuze afirma que "não pensamos sem devir outra coisa, qualquer coisa que não pensa, um animal, um vegetal, uma molécula, uma partícula, as quais regressam ao pensamento e o relançam" ${ }^{20}$. Ou seja, o pensamento está sempre confrontado com o risco, com o perigo iminente de total perdição no caos. Esse seria o ponto de não-retorno catastrófico. Mas o movimento natural do pensamento faz-se sempre nesse risco, porque o pensamento é precisamente esse movimento de composição com o caos. E nesse movimento, o pensamento devém outras entidades para regressar a si mesmo, sempre outro.

Para percebermos ainda melhor este dinamismo modulador da virtualização e da ontologia imanente, é necessário ter em conta uma das teses mais fortes e presentes em toda a obra de Deleuze: a tese, que Deleuze recupera de Duns Escoto, da univocidade do ser e do pensamento ${ }^{21}$. Em oposição a uma ontologia da essência e da transcendência, onde há uma clara distância ontológica entre o ser e o pensamento como dois termos

20. Gilles Deleuze e Félix Guattari, Qu'est-ce que la Philosophie ?, 44.

21. “O Tudo é igual e o Tudo retorna só podem ser ditos lá onde o ponto extremo da diferença for alcançado. Uma única e a mesma voz para todo o múltiplo a mil caminhos, um único e o mesmo Oceano para todas as gotas, um único clamor do Ser para todos os seres. Na condição de ter alcançado para cada ser, para cada gota e em cada caminho, o estado de excesso, isto é, a diferença que os desloca e disfarça" (Gilles Deleuze, Différence et Répétition, 388-9). 
opostos, um como matéria, outro como espírito, Deleuze propõe uma ontologia da diferença na qual o caos e o pensamento têm existência física. Como escreve em Qu'est ce que la Philosophie? : "o caos (...) tem tanto uma existência mental quanto física" 22 . O objectivo desta ontologia é, acima de tudo, fornecer a base para uma teoria construtivista e imanentista da realidade, em que o processo de actualização de uma ideia, o processo do devir do pensamento, o processo de composição com o caos, seja matéria e movimento. Ou seja, o movimento do pensamento, quando se dirige a um problema, é um movimento que deve ser entendido na sua máxima fisicalidade. Como Deleuze explica, pensar "não implica apenas o virar-se para, mas o confrontar, fazer volte-face, voltar-se, perder-se, apagar-se"23.

E aqui, Deleuze e Guattari retomam o termo de "chaosmos" inventado por James Joyce, em Finnegans Wake (1939), para designar essa "identidade interna do mundo e do caos" 24 . A afirmação de um mundo formado como caosmos é expressão de um plano de composição (e não um dado preconcebido, universal) do caos e com o caos. Ou seja, o caos faz parte, tanto do mundo, da matéria, quanto do pensamento. Dito de outro modo: O que é primeiro, de certa forma, é o caos. E, como Deleuze afirma no seu célebre comentário de Hume, "o fundo do espírito é delírio, ou, o que significa o mesmo segundo outros pontos de vista, acaso, indiferença” 25 .

Ora, esse caos torna-se pensamento, adquire uma realidade enquanto pensamento ou caosmos mental. "O que o filósofo tira do caos, são as variações que continuam infinitas, mas que se tornaram inseparáveis (...). O cientista tira do caos variáveis que se tornaram independentes (...) o artista tira do caos variedades"26. Assim, ciência, arte e filosofia são as três formas de pensamento e as três formas de recortar e de criar o caos. Sobre o plano de imanência produz-se a filosofia, sobre o plano de consistência, a ciência e sobre o plano de composição, a arte. Por isso é que Deleuze e Guattari afirmam que ciência, arte e filosofia são as três caóides do

22. Gilles Deleuze e Félix Guattari, Qu'est-ce que la Philosophie?, 45.

23. Gilles Deleuze e Félix Guattari, Qu'est-ce que la Philosophie?, 41.

24. Gilles Deleuze, Différence et Répétition,1968, 382. Como explica Manola Antonioli: "trata-se da afirmação da univocidade do ser, na qual já não existe diferença de natureza entre os seres, mas apenas diferenças de potência ou de intensidade. O Ser-igual não é neutro, indiferenciado, mas atravessado por intensidades, em diferenciação e em devir perpétuos. Tudo o que tem lugar, tem lugar a partir desse caosmos que não é feito senão de diferenças" [Manola Antonioli, Deleuze et l'Histoire de la Philosophie (Paris: Kimé, 1999], 98-99.

25. Gilles Deleuze, Empirisme et Subjectivite (Paris : PUF, 1953), 4.

26. Gilles Deleuze e Félix Guattari, Qu'est-ce que la Philosophie?, 190. 
pensamento, ou seja, os três tipos diferentes de realidades que se formam como pensamento a partir do caos. "O caos tem três filhas segundo o plano que o recorta: são as caóides, a arte, a ciência e a filosofia, como formas de pensamento e criação" 27 . Sobre cada plano que recorta o caos, produz-se uma realidade própria, um anti-caos objectivo, ou seja, uma ideia ordenada que se designa como conceito, em filosofia, como função, em ciência, como afecto, em arte.

\section{Que consequências desta relação entre pensamento e caos para a compreensão da Ciência, da Arte e da Filosofia?}

Vimos como, para Deleuze, o caos é uma condição da possibilidade do pensamento. Ora, ciência, arte e filosofia, como as três filhas desse campo primeiro de chaosmos, têm formas diferentes de se relacionar com o caos. Como iremos ver de seguida, cada uma delas corta o caos de modo específico e extrai dele matérias distintas.

A filosofia é a arte de formar, de inventar, de fabricar conceitos. Ora, "o conceito define-se pela inseparabilidade de um número finito de componentes heterogéneas percorridas por um ponto em sobrevoo absoluto, a uma velocidade infinita"28. Deleuze e Guattari definem o conceito como sendo simultaneamente absoluto e relativo. Relativo, face às suas próprias componentes, aos outros conceitos, ao plano no qual se delimita, aos problemas que é suposto resolver. Absoluto pela condensação que opera, pelo lugar que ocupa no plano, pelas condições que marca ao problema. "O conceito define-se pela sua consistência, endo-consistência e exo-consistência, mas não tem referência: é auto-referencial, põe-se a si próprio e põe o seu objecto"29.

A filosofia dá consistência ao caos no conceito, mas mantendo o infinito do caos, isto é, compõe com a virtualidade do caos, na sua totalidade, na sua infinitude. "A filosofia pergunta como guardar as velocidades infinitas enquanto ganha consistência, ao dar uma consistência própria ao virtual" ${ }^{30}$. A filosofia é o confronto do pensamento com um dilema de base que, segundo Deleuze, está presente em toda a história da filosofia: a escolha entre o caminho da transcendência ou o caminho

27. Gilles Deleuze e Félix Guattari, Qu'est-ce que la Philosophie ?, 196.

28. Gilles Deleuze e Félix Guattari, Qu'est-ce que la Philosophie ?, 26.

29. Gilles Deleuze e Félix Guattari, Qu'est-ce que la Philosophie ?, 27.

30. Gilles Deleuze e Félix Guattari, Qu'est-ce que la Philosophie?, 112.

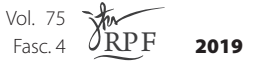


do $\operatorname{caos}^{31}$. A Filosofia é sempre essa capacidade de incorporar o caos, trabalhar com o caos na sua infinitude, como plano de imanência. Daí a diferença entre filosofia e religião, pois esta remete sempre o pensamento para a zona da transcendência. Pelo contrário, a filosofia encara de frente a imanência, incorporando assim o caos como elemento e risco do pensamento. "Os primeiros filósofos são aqueles que instauram um plano de imanência como uma peneira esticada em direção ao caos. Neste sentido, eles opõem-se aos Sábios, que são personagens da religião, os padres, porque estes concebem a instauração de uma ordem sempre transcendente"32. Isto é, a filosofia é uma luta contra os abismos do pensamento, ou, como diria Kant, contra os limites e as ilusões da razão pura.

Mas o que significa então traçar um plano sobre o caos? Significa criar uma imagem do pensamento, o qual ganha forma e se determina como conceito, extraindo-se assim da indeterminação geral do caos que seria do domínio da mera opinião ou do delírio absoluto e improdutivo. O pensamento ganha forma, não porque o plano que o filósofo traça seja o plano das regras lógicas e constantes do pensamento, das associações de ideias pela analogia, contiguidade ou causalidade, mas porque traçar o plano contém sempre uma parte caótica, é sempre uma composição com o caos. "O conceito é um conjunto de variações inseparáveis, que se produz ou se constrói sobre um plano de imanência, na medida em que este recorta a variabilidade caótica e lhe dá consistência (realidade). Um conceito é, pois, um estado caóide por excelência; remete a um caos tornado consistente, tornado Pensamento, caosmos mental. E que seria pensar se não se comparasse sem cessar com o caos?" ${ }^{33}$. De facto, para Deleuze, o plano de instauração como solo da atividade criativa em filosofia não existe fora do caos. Ele "implica uma espécie de experimentação tateantes, e o seu traçado recorre a meios pouco aceitáveis, pouco racionais e razoáveis. São meios da ordem do sonho, de processos patológicos, de experiências esotéricas, de bebedeira e de excesso (...). Pensar é sempre seguir uma linha de bruxa" ${ }^{34}$. Há, portanto, uma dobra imanente entre plano e caos. Formado no interior do caos e com o caos, o plano é, no entanto, exterior a ele. E esse processo de corte do caos enquanto instauração de um plano

31. Cf. Gilles Deleuze e Félix Guattari, Qu'est-ce que la Philosophie ?, 52.

32. Gilles Deleuze e Félix Guattari, Qu'est-ce que la Philosophie ?, 45.

33. Gilles Deleuze e Félix Guattari, Qu'est-ce que la Philosophie?, 195-6.

34. Gilles Deleuze e Félix Guattari, Qu'est-ce que la Philosophie ?, 44. 
é um processo de experimentação de várias intensidades do pensamento que muitas vezes extrapolam a fronteira entre o normal e o patológico.

Traçar um plano sobre o caos é o gesto de instauração da filosofia, é a condição de qualquer criação da imagem do pensamento, uma vez que o plano é pré-filosófico. Na sua prática criativa, "o conceito é o começo da filosofia, mas o plano é a sua instauração"35. No entanto, é necessário esclarecer que "pré-filosófico" não significa que o plano exista antes, como condição transcendente à filosofia. O plano é designado por pré-filosófico, não por ser transcendente, mas por ser pressuposto. O plano é condição do pensamento, não enquanto condição transcendente, ideal ou possível, mas enquanto condição imanente, actual e material: o plano é composição com a matéria do caos. Assim, a filosofia faz-se sempre num movimento triplo, naquilo a que Deleuze denomina de trindade filosófica: traçar, inventar, criar ${ }^{36}$.

A filosofia traça o plano de imanência que apresenta a imagem do pensamento, em cujo horizonte os conceitos são criados. Não como criação do absolutamente novo e a partir do nada, mas sempre au millieu. Os conceitos fazem-se sempre no meio de outros conceitos, no dinamismo do caos. Têm uma génese intempestiva. Como vimos, há sempre um risco no caos. Daí que Deleuze advirta que o pensamento luta permanentemente por articular qualquer coisa de coerente, para cortar o caos e assim vencer o domínio do senso comum ou da opinião. Como escreve: "Pedimos apenas alguma ordem para nos protegermos do caos. Nada é mais doloroso, mais angustiante, do que um pensamento que se escapa a si mesmo, ideias que fogem, que desaparecem mal ainda esboçadas, já corroídas pelo esquecimento ou precipitadas noutras, que também não dominamos (...). Estamos constantemente a perder as nossas ideias. É por isso que nos queremos apegar a opiniões fixas" ${ }^{37}$.

Resta saber de que modo a ciência, a arte e a filosofia se articulam com o caos e enfrentam o seu perigo. "Mas arte, ciência, filosofia exigem mais: elas traçam planos sobre o caos. Estas três disciplinas não são como religiões que invocam dinastias de deuses, ou a epifania de um único deus para pintar no topo um firmamento do qual derivassem as nossas opiniões. Filosofia, ciência e arte querem que destruamos o firmamento e

35. Gilles Deleuze e Félix Guattari, Qu'est-ce que la Philosophie ?, 44.

36. Gilles Deleuze e Félix Guattari, Qu'est-ce que la Philosophie ?, 74.

37. Gilles Deleuze e Félix Guattari, Qu'est-ce que la Philosophie?, 189. 
mergulhemos no caos. Só o iremos ganhar a esse preço"38. Eis a solução proposta por Deleuze: mergulhar no caos. Só assim conseguiremos retirar o caos da sua maldição. É preciso mergulhar no caos para dele extrair o conceito, na filosofia, a função, na ciência, e o afecto, na arte ${ }^{39}$.

Por seu lado, a ciência opera por funções, as quais dizem respeito aos estados de coisas, a objectos ou corpos individuados, sejam eles uma nuvem ou um fluxo, e num tempo classificável. Como Deleuze e Guattari escrevem, a função pretende "isolar variáveis num ou noutro instante, ver quando novas variáveis intervêm a partir de um potencial, em que relações de dependência podem entrar, por que singularidades passam, que limiares transpõem" ${ }^{40}$. Quer dizer, a ciência ocupa-se do caos no sentido de tentar compreendê-lo, ordená-lo, extrair dele funções, encontrar variáveis independentes, constantes e limites, que lhe permitam regular os estados de coisas ou um sistema actual e num tempo entre dois instantes ou tempos entre muitos instantes. Ela segue um movimento descendente, do caos virtual aos estados de coisas, isto é, actualiza os estados de coisas num corpo, num tempo e num espaço singulares. A ciência renuncia, portanto, às velocidades infinitas do caos, tenta sempre estabelecer pontos de referência, como que balizando o caos, objectivando-o numa função. "O cientista traz do caos variáveis, tornadas independentes por desaceleração, isto é, por eliminação de outras variabilidades quaisquer, suscetíveis de interferir, de modo que as variáveis retidas entram em relações determináveis numa função" ${ }^{41}$.

É este movimento descendente do caos virtual às coisas, num espaço e num tempo determináveis, que Deleuze e Guattari descrevem como sendo a criação de um plano de referência, próprio da ciência. Plano esse com que os cientistas combatem as superstições, as falsas proposições ou as pseudociências. Enquanto a ciência consegue retardar o caos e impor-lhe limites, dando-lhe uma referência, a arte tem uma luta diferente da ciência: não contra o caos, mas contra os clichés que povoam antecipadamente qualquer tela em branco. A arte tem um procedimento

38. Gilles Deleuze e Félix Guattari, Qu'est-ce que la Philosophi e?, 190.

39. "O que o filósofo traz do caos são variações que permanecem infinitas, mas tornadas inseparáveis sobre superfícies ou em volumes absolutos, que traçam um plano de imanência secante: não mais associações de ideias distintas, mas re-encadeamentos, por zona de indistinção, num conceito" (Gilles Deleuze e Félix Guattari, Qu'est-ce que la Philosophie?, 190).

40. Gilles Deleuze e Félix Guattari, Qu'est-ce que la Philosophie ?, 148.

41. Gilles Deleuze e Félix Guattari, Qu'est-ce que la Philosophie?, 190.

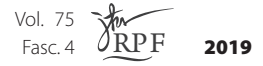


diferente: compõe com o caos, integra-o no seu processo criativo de forma a captar visões e audições, de forma a compor novas sensações. A filosofia, por sua vez, luta como a ciência contra o domínio da opinião ${ }^{42}$. Ciência, arte e filosofia têm, portanto, uma diferente relação, não apenas com o caos, mas com o infinito. "O crivo filosófico, como plano de imanência que recorta o caos, seleciona movimentos infinitos do pensamento, e fornece-se de conceitos formados como de partículas consistentes que vão tão rápido como o pensamento. A ciência tem uma forma completamente diferente de abordar o caos, quase inversa: ela renuncia ao infinito, à velocidade infinita, para ganhar uma referência capaz de actualizar o virtual. Guardando o infinito, a filosofia dá uma consistência ao virtual por conceitos; renunciando ao infinito, a ciência dá ao virtual uma referência que o actualiza, por funções. A filosofia procede com um plano de imanência ou de consistência; a ciência com um plano de referência"43.

Que caminho, entre as duas linhas da ciência e da filosofia, pode a arte seguir ? Ao criar obras de arte, o artista cria estados de coisas, não para actualizar ou efectivar uma virtualidade, mas para a contra-efectuar, para atingir e ir ao encontro do virtual, para tornar sensível a parte do acontecimento que não se actualiza. A arte produz obras de arte como estados de coisas, não para as ordenar, mas para lhes dar caos, para igualar o infinito, para exprimir o virtual, em suma, para extrair a sua parte não-efectuável, intemporal, a sua parte que constitui a própria realidade do virtual.

Podemos, portanto, dizer que a arte vai nos dois sentidos ao mesmo tempo. Ela cria o actual, mas para libertar o virtual, ela trabalha sobre os estados de coisas, mas para fazer surgir acontecimentos. No entanto, a arte não é uma síntese das duas linhas. "Os três pensamentos cruzam-se, entrelaçam-se, mas sem síntese nem identificação. A filosofia faz surgir acontecimentos com os seus conceitos, a arte compõe monumentos com as suas sensações, a ciência constrói estados de coisas com as suas funções" ${ }^{\text {" }}$. O artista quer extrair do caos uma obra de arte, isto é colocar o infinito no finito. A obra de arte é um composto de caos. A obra de arte é esse monumento que se sustenta por si próprio, materializando as forças de caos, de infinito e de sensações, afectos e perceptos que o atravessam. Através delas

42. Como escreve Deleuze: "A luta com o caos não é senão o instrumento de uma luta mais profunda contra a opinião, pois é da opinião que surge a infelicidade dos homens" (Gilles Deleuze e Félix Guattari, Qu'est-ce que la Philosophie?, 194). Sobre esta questão, cf. Gilles Deleuze e Félix Guattari, Qu'est-ce que la Philosophie ?, 190-195.

43. Gilles Deleuze e Félix Guattari, Qu'est-ce que la Philosophie?, 112.

44. Gilles Deleuze e Félix Guattari, Qu'est-ce que la Philosophie?, 187-8. 
o artista enfrenta o cliché, o banal. "O artista traz do caos variedades, que não constituem mais uma reprodução do sensível no órgão, mas erigem um ser do sensível, um ser de sensação, sobre um plano de composição anorgânico, capaz de restituir o infinito"45.

A arte é o plano de composição que recorta sensações do caos. Há portanto um movimento aparentemente contraditório na arte, a qual vai sempre nos dois sentidos ao mesmo tempo : da sensação composta ao plano de composição como corte do caos, como movimento de definição determinada (finito); e do plano de composição à sensação composta como movimento de infinito. Entre a sensação e o plano existe uma estrita coexistência e complementaridade, os dois formam-se e compõem-se ao mesmo tempo, correlativamente. Este duplo movimento da arte entre o finito e o infinito, os quais constituem o plano de composição como corte do caos, é o que sustende a definição da arte como pensamento. Segundo Deleuze e Guattari, a arte é um pensamento, a arte pensa tanto quanto a filosofia ou a ciência. A filosofia dá consistência ao caos e tenta salvar o infinito. A ciência, pelo contrário, renuncia ao infinito. Ela dá-lhe uma referência de modo a transformá-lo numa função, numa coordenada determinável. A arte cria o finito com o infinito, dando uma vida materializada a esse composto misto. Estes diferentes modos de pensar e de confrontar o caos, não são mais do que a constatação do caos como uma realidade em si. Desde o ser vivo à obra de arte, há uma auto-posição do criado. Por isso, recortar o caos, torná-lo consistente, é conferir-lhe uma realidade própria. É conferir-lhe uma objetividade e uma auto-posição.

Apesar de terem traçado as diferenças entre filosofia, arte e ciência, Deleuze e Guattari manifestam a sua preocupação em perceber as suas relações e modos de partilha. O final do capítulo "Functivos e Conceitos", que estabelece de forma clara as várias linhas de fronteira entre filosofia e ciência, termina com a manifestação dessa preocupação. "O estatuto dos perceptos e dos afectos puros ainda nos escapa, reenviando à existência das artes. Mas justamente, que haja perceções e afeções propriamente filosóficas, e propriamente científicas, sensibilia de conceito e de função, indica já o fundamento de uma relação entre, por um lado, a ciência e a filosofia, por outro, a arte, de tal modo que podemos dizer que uma função é bela e que um conceito é belo. As percepções e afeções especiais da filosofia ou da ciência se aproximarão necessariamente aos perceptos e afectos da arte" ${ }^{46}$.

45. Gilles Deleuze e Félix Guattari, Qu'est-ce que la Philosophie ?, 190. Cf. também 192.

46. Gilles Deleuze e Félix Guattari, Qu'est-ce que la Philosophie?, 126. 


\section{Conclusão ou dos intercessores}

Em Pourparlers, Deleuze diz: "O essencial são os intercessores. A criação é os intercessores. Sem eles, não há obra. Podem ser pessoas para um filósofo, artistas ou cientistas; para um cientista, filósofos ou artistas - mas também coisas, plantas e até animais, como em Castaneda. Fictícios ou reais, animados ou inanimados, é necessário fabricar os seus intercessores. É uma série. Se não formarmos uma série, mesmo completamente imaginária, estaremos perdidos. Preciso dos meus intercessores para me expressar, e eles nunca se expressariam sem mim: trabalhamos sempre a muitos, mesmo quando isso não se vê. Especialmente quando é visível: Félix Guattari e eu somos intercessores um do outro" ${ }^{47}$.

Literatura, cinema, pintura, biologia, economia, geologia, e tantas outras áreas disciplinares são os intercessores da filosofia. Arte e ciência são o "fora" da filosofia com quem ela está em constante relação, interação, intersecção. É a essas intercessões que a filosofia vai buscar ideias, imagens, problemas para construir, com eles, os seus conceitos filosóficos ${ }^{48}$. A filosofia transcendental Kantiana teve em Newton um intercessor activo. Do mesmo modo, é às intercessões com a arte e a filosofia que a ciência recorre para, com elas, criar as suas funções. A investigação de António Damásio na área das neurociências teve explícitos intercessores activos em Descartes e Spinoza ${ }^{49}$. E é com as intercessões da ciência e da filosofia que a arte vai compor os seus afectos e perceptos. A poesia Oulipo nasce de um fascinante encontro com a matemática. Fazer poesia é pôr em funcionamento "o implacável rigor e a delirante fantasia que anima a Teoria dos Números" ${ }^{50}$. Os exemplos são inúmeros. Se há hoje uma disciplina que se designa por "Ciência e Arte" (Sci-Art) e, se, no seu interior, se destaca uma florescente actividade híbrida que dá pelo nome de Bio-Arte,

47. Gilles Deleuze, Pourparlers (Paris : Minuit, 1990), 171.

48. Como escreve Simone Brott, "o intercessor não é simplesmente uma conduta para a informação, um mediador silencioso, mas (...) literalmente um 'estando-entre' ("goingbetween”). (Simone Brott, Deleuze and “The Intercessors”, $\log \mathrm{n}^{\circ} 18$ (2010), 138.

49. Cf. de António Damásio, Ao Encontro de Espinosa. As Emoções Sociais e a Neurologia do Sentir, Mem-Martins: Europa-América, 2003 e O erro de Descartes. Emoção, Razão e Cérebro Humano, Lisboa: Círculo de Leitores, 2011.

50. François Le Lionnais, "Raymont Queneau et l'Amalgame des Mathématiques et de la Littérature", in Atlas de Littérature Potentielle, editado por Oulipo, (Paris : Gallimard, 1981), 36 . 
é porque esta intercepção está amplamente identificada e adquiriu hoje uma inaudita pregnância ${ }^{51}$.

Mas é importante ressaltar que a filosofia não tem uma relação de verticalidade com os seus intercessores, a filosofia não é uma análise $a$ posteriori em que o filósofo discorre sobre as obras de arte ou os processos e resultados das ciências, mas antes uma atividade horizontal, que produz os seus conceitos sempre numa relação de horizontalidade com as ciências e as artes. Deleuze diz isso mesmo muito claramente na conferência "Qu'est ce que l'Acte de Création?" de que só existe registo oral e da qual transcrevemos a seguinte passagem: "a filosofia não é feita para refletir sobre tudo e mais alguma coisa. Não é feita para refletir sobre outra coisa. Quero dizer, tratando a filosofia como uma potência para refletir sobre, parece que lhe damos muito, mas, de facto, removemos-lhe tudo. Porque ninguém precisa de filosofia para refletir. Quero dizer, as únicas pessoas que conseguem, efetivamente, refletir sobre cinema são os cineastas, ou os críticos de cinema ou os amantes de cinema. Eles não precisam de todo da filosofia para refletir sobre cinema. A ideia de que os matemáticos precisariam de filosofia para refletir sobre matemática é uma ideia cómica. Se a filosofia precisasse de refletir sobre alguma coisa, então não teria qualquer razão para existir. Se a filosofia existe, é porque tem o seu próprio conteúdo. Se perguntarmos: qual é o conteúdo da filosofia? É muito simples. A filosofia é uma disciplina tão criativa e inventiva quanto qualquer outra disciplina. A filosofia é uma disciplina que consiste em criar ou inventar conceitos. E os conceitos não existem já feitos. Os conceitos não existem num tipo de céu onde eles esperariam que um filósofo os agarrasse. Os conceitos têm de ser fabricados" ${ }^{52}$.

Ou seja, cada área disciplinar pensa por si mesma, tem a capacidade de pensar autonomamente sobre si própria e sobre os problemas com que se defronta. A literatura não precisa da filosofia para pensar a literatura. Fernando Pessoa ou Joyce não são apenas grandes poetas e grandes escritores. São também grandes pensadores da literatura. A biologia pensa a vida sem para isso precisar da filosofia. Que fizeram Geofroy de St. Hilaire, Lineu ou Darwin senão pensar a vida?

51. Bastará referir os trabalhos pioneiros de arte transgénica realizados por Eduardo Kac e o questionamento da responsabilidade ética que o conhecido artista brasileiro tem vindo a desenvolver. Sobre Eduardo Kac, cf., por exemplo, <https://www.ekac.org/ kac2.html>

52. Gilles Deleuze "Qu'est-ce que l'Acte de Création ?" <https://www.youtube.com/ watch?v=2OyuMJMrCRw > acedido a 23 de novembro de 2019.

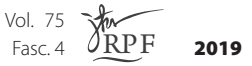


Deleuze quer deixar absolutamente clara esta ideia: a filosofia não serve para refletir "sobre" ${ }^{3}$. Nem sobre matemática, nem sobre pintura, nem sobre qualquer outra actividade artística ou científica. A filosofia não serve para reflectir "sobre" mas para pensar "com". Deleuze dedicou grande parte da sua obra a pensar, não "sobre", mas "com" obras literárias, com pinturas, com música, com biologia, com geologia, com cinema. Tanto em livros a pensar "com" a pintura de Francis Bacon, ou "com" a literatura Becket ou de Carmelo Bene, como em encontros intensos, mas breves, em aproximações vertiginosas, em confluências pontuais, com a música de Messian, a pintura de Van Gogh, com a escrita de Tournier, Lewin Carroll, Virginia Woolf, ou com a poesia de Bob Dylan. A filosofia não é, nem reflexão, nem contemplação platónica do mundo das ideias, nem comunicação das opiniões e ou dos consensos ${ }^{54}$. A filosofia é antes uma atividade criativa, uma fábrica de conceitos.

A criação de conceitos passa pela contaminação, pelo contágio, pela aliança entre conceitos, ideias ou problemas. A filosofia encontra na ciência ou na arte os mesmos problemas com que se depara. Com a pintura de Francis Bacon, é a possibilidade de uma lógica das sensações que é pensada por Deleuze. As obras literárias, por exemplo, de Proust e Kafka funcionam mesmo como verdadeiros laboratórios transcendentais, lugares de experimentação de figuras, de problemas, de formas "com" as quais a filosofia de Deleuze se vai constituindo ${ }^{55}$. Ou seja, a filosofia faz-se de intercessões com saberes não-filosóficos: a arte e a ciência ${ }^{56}$. Deleuze vai mesmo mais longe ao afirmar que a criação passa pela apropriação ou "roubo" de conceitos de outros filósofos. Não se trata de citar, de parafrasear ou pôr entre aspas, mas de compor "com", de entrar numa zona de

53. Como Deleuze afirma: "o conceito não reflete sobre a função, tal como a função não se aplica ao conceito (...): é por isso que é sempre triste que os cientistas façam filosofia sem um meio realmente filosófico, ou que os filósofos façam ciência sem um meio efetivamente científico" (Gilles Deleuze e Félix Guattari, Qu'est-ce que la Philosophie?, 146).

54. Cf. Gilles Deleuze e Félix Guattari, Qu'est-ce que la Philosophie?, 11-2.

55. Sobre esse estatuto de laboratórios transcendentais com que as obras literárias se oferecem ao pensamento de Deleuze, cf. Catarina Pombo Nabais, Gilles Deleuze: Philosophie et Litterature, (Paris : Harmattan, 2013).

56. Sobre as controversas relações de Deleuze com as ciências, cruelmente fustigadas pelo famoso artigo de Sokal e Bricmont, Imposturas Intelectuais. (Lisboa : Gradiva, 1999), refiram-se alguns dos estudos mais relevantes: Manuel Delanda, Intense Science and Virtual Philosophy, (London/New York: Continuum Books, 2002), John Protevi, Life, War, Earth: Deleuze and the Sciences, (Minnesota: Minnesota University Press, 2013), Mark Bonta, Deleuze and Geophilosophy, (Edinburg: Edinburg Press, 2004) e ainda o volume editado por John Marks, Deleuze and Science, (Edinburg: Edinburg University Press, 2006). 
indiscernibilidade, de vizinhança, de cruzamento entre pensamentos. É com Spinoza que Deleuze se encontra com o conceito de expressão. É aos estóicos que Deleuze "rouba" o conceito de acontecimento. Como Deleuze sugere, utilizando um verso do músico e poeta Bob Dylan, um filósofo é "um ladrão de ideias". Mas adverte: "Roubar é o contrário de plagiar, de copiar, de imitar ou de fazer como"57.

De facto, da mesma forma que o pensamento não é uma actividade voluntária, "ter uma ideia" também não resulta de um acto de vontade. A ideia não é uma precondição espontânea de uma faculdade. A ideia é antes o resultado de um conjunto de circunstâncias, de encontros. Apesar da solidão que assola o filósofo na sua mesa de trabalho, o artista diante da tela ou o cientista na bancada do laboratório, estas três figuras da criação estão sempre acompanhadas por uma multidão. O pensamento está sempre povoado por ideias dos outros, por acontecimentos exteriores, por entidades diversas, pelo mundo lá fora. Como Deleuze escreve numa passagem de grande beleza, "Quando trabalhamos, estamos necessariamente em absoluta solidão (...). Só que é uma solidão extremamente povoada. Não é povoada com sonhos, fantasias ou projetos, mas de encontros. Um encontro é talvez o mesmo que um devir ou um esponsal. É do fundo dessa solidão que podemos fazer qualquer encontro. Encontramos pessoas (e algumas vezes sem as conhecer ou sem nunca as termos visto), mas também movimentos, ideias, acontecimentos, entidades" 58 .

Mas, para lá da captura e do roubo, esse encontro tem também a forma da convivência feliz num espaço híbrido, da vizinhança e da partilha. "Encontrar é achar, é capturar, é roubar, mas não há método para encontrar, nada além de uma longa preparação. Roubar é o contrário de plagiar, copiar, imitar ou fazer como. A captura é sempre uma captura dupla, o voo um voo duplo, e é isso que torna, não algo mútuo, mas um bloco assimétrico, uma evolução paralela, um casamento, sempre 'fora' e 'entre"'59. Deleuze, ele mesmo, é conhecido por ser um magnífico comentador de outros filósofos. Aliás, tornou-se mesmo um cliché reconhecer em Deleuze proposições de outros autores. Nos seus textos, encontramos sempre referência a outros autores como Espinosa, Hume, Nietzsche, Bergson ou Kant. É de facto impossível explicar as teses e conceitos mais

57. Gilles Deleuze e Claire Parnet, Dialogues, (Paris : Flammarion, 1977), 13.

58. Gilles Deleuze e Claire Parnet, Dialogues, 13.

59. Gilles Deleuze e Claire Parnet, Dialogues, 13. 
singulares de Deleuze, como o seu programa de empirismo transcendental, ou os conceitos de plano de imanência, virtual, univocidade do ser, etc., sem sermos de imediato forçados a pensar no "Bergson" de Deleuze ou no "Espinosa" de Deleuze"60.

A própria colaboração intensiva com Félix Guattari veio tornar mais evidente ainda o que Deleuze chama de método de collage na história da filosofia e que teria permitido "um Hegel filosoficamente barbudo, um Marx filosoficamente calvo como uma Gioconda com bigodes ${ }^{61}$ ". Foi para potenciar essa collage que Deleuze dedicou a década de 70 a trabalhos de economia política, sociologia, linguística, literatura, psicanálise, biologia, ou seja, a uma mistura vertiginosa de saberes e disciplinas como meio necessário para fazer filosofia e, portanto, criar novos conceitos. A filosofia, segundo Deleuze, é esse campo poroso, sempre invadido, contaminado, por perspectivas não-filosóficas. Deleuze diz que a filosofia pensa "com" a ciência e a arte. A filosofia desenvolve um pensamento que se faz "entre" a filosofia e a arte ou a ciência.

Contudo, não podemos deixar de notar que, apesar de Deleuze ter pensado a arte, a ciência e a filosofia como sendo as três filhas de um mesmo pensamento, as três caóides, e, apesar de ter pensado os processos de devir do próprio pensamento como sendo transversais à arte, à ciência a filosofia, o que é certo é que, no momento de exemplificar esse contágio, Deleuze apresenta sobretudo o exemplo da filosofia. É a filosofia que Deleuze, retomando a expressão de Foucault, diz que pensa autrement. É na filosofia que, de forma predominante, quase exclusiva, Deleuze descreve o contágio do pensamento. Teremos de o condenar por isso? Será que, afinal, Deleuze se mantém no interior da tradição filosófica que faz da filosofia o lugar privilegiado do pensamento? Pensamos que não. Afinal, o livro onde Deleuze estabelece as relações entre ciência, arte e filosofia tem por título “O que é a filosofia?”. Ou seja, neste livro, Deleuze coloca-se do lado da filosofia e, portanto, só refere a ciência e a arte para estabelecer as diferenças com a filosofia. O seu trabalho não é aquele que poderia ser feito a partir da ciência ou da arte. Nem poderia afinal ser de outro modo. Fazer de outro modo, seria continuar a colocar-se na posição tradi-

60. Para Deleuze, referir-se a alguém supõe sempre uma intersecção, uma interferência com. Sobre a intersecção como condição da criação do pensamento cf. Pourparlers, 170-171; Dialogues, 13; Gilles Deleuze, L'Image-Temps, (Paris: Minuit, 1985), 365: "É no nível da interferência de muitas práticas que as coisas são feitas, seres, imagens, conceitos, todos os tipos de eventos").

61. Gilles Deleuze, Différence et Répétition, 4. 
cional que faz da filosofia o lugar por excelência do pensamento da arte e do pensamento da ciência. O que Deleuze procura é sair da filosofia pela própria filosofia. O que implica um duplo movimento, uma abertura e um fechamento: arrastar o conceito até ao limite daquilo que já não é filosofia, mas arte e ciência, isto é, abrir a filosofia à não-filosofia e, em simultâneo, fazer filosofia, isto é, fabricar conceitos. Inclusive, os conceitos de arte, de ciência e de filosofia.

Ora, apesar de, no livro Qu'est ce que la Philosophie?, Deleuze deixar ver a ambiguidade da tarefa a que se entrega, é impossível não reconhecer a boa vontade que salva o seu projecto de tornar a ciência, a arte e a filosofia, tarefas horizontais, irmãs em pensamento criativo e em composição do caos. É nesta linha que este artigo se situa. Ele pretende alargar à ciência e à arte esta vocação de transversalidade que Deleuze acaba por atribuir sobretudo à filosofia. Ou seja, não é só a filosofia que se deixa infiltrar pelo "fora", isto é, pela ciência e pela arte. Esse campo de devir, de contágio, acontece também, mesmo que de forma menos evidente, no próprio trabalho científico e artístico. O que Deleuze descreve como processo específico da filosofia, pode ser aplicado, de forma mais afirmativa, horizontal e igualitária, tanto à ciência como à arte. Apesar das diferenças que as distinguem, ciência, arte e filosofia entrelaçam-se, funcionam em rede, em relação. E, como Deleuze escreve em Pourparlers: "O que me interessa são as relações entre as artes, a ciência e a filosofia" 62 .

O importante nesta permeabilidade, não é a exatidão das referências, mas os efeitos que elas produzem nos campos contaminados. O importante são os seus efeitos no pensamento: os devires, os voos, os processos de criação. E o importante é também o facto de ser através do encontro que o pensamento tem a experiência do devir. Ou seja, não é importante averiguar se, por exemplo, o artista está a usar corretamente a função científica ou o cientista a sensação artística. O importante é que haja contaminação. O importante é "pensar de outro modo": fazer filosofia como Einstein resolve uma equação ou como Van Gogh pinta A noite estrelada. Partilhar os mesmos processos de criação.

O constructivismo com que Deleuze define a filosofia, é um constructivismo múltiplo, a várias vozes, um plano de mistura, de diferença, de aliança com a não-filosofia. Um constructivismo que pensamos poder ser extrapolado para o campo da ciência e da arte. Podemos assim dizer a filosofia precisa de uma não-filosofia, tal como a ciência precisa de uma

62. Gilles Deleuze, Pourparlers, 168.

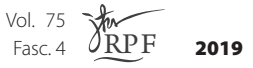


não-ciência e a arte precisa de uma não-arte. O conceito de "intercessores" é, pois, fundamental para pensar a relação entre filosofia, ciência e arte. Os planos do pensamento, o plano de composição da arte, o plano de referência da ciência e o plano de imanência da filosofia estabelecem-se nessa relação do pensamento com os seus intercessores. Sem eles não seria possível o processo de criação de conceitos, de funções e de afectos.

Terminamos com uma longa, e muito luminosa, citação de Deleuze de Pourparlers:

Essa ideia de que a verdade não é algo que preexiste, que deve ser descoberto, mas algo que deve ser criado em cada domínio é evidente, por exemplo, nas ciências. Mesmo na física, não há verdade que não suponha um sistema simbólico, mesmo que apenas se trate de coordenadas. Não há verdade que não 'falsifique' ideias pré-estabelecidas. Dizer: 'a verdade é uma criação’ implica que a produção da verdade passa por uma série de operações que consistem em trabalhar uma matéria, uma série de falsificações à la lettre. O meu trabalho com Guattari: cada um é o falsificador do outro, o que significa que cada um entende à sua maneira a noção proposta pelo outro. Forma-se assim uma série reflexiva, a dois termos. Não está excluída uma série com vários termos, ou séries complicadas, com bifurcações. Essas potências do falso que vão produzir o verdadeiro, é isso que são os intercessores... ${ }^{63}$.

\section{Referências}

Antonioli, Manola. Deleuze et l'Histoire de la Philosophie. Paris : Kimé, 1999.

Bonta, Mark. Deleuze and Geophilosophy. Edinburg: Edinburg Press, 2004.

Brott, Simone, Deleuze and "The Intercessors", Log. 18 (2010), 135-151.

Damásio, António, Ao Encontro de Espinosa. As Emoções Sociais e a Neurologia do Sentir, Mem-Martins: Europa-América, 2003.

Damásio, António, O Erro de Descartes. Emoção, Razão e Cérebro Humano, Lisboa: Círculo de Leitores, 2011.

Delanda, Manuel. Intense Science and Virtual Philosophy, London/New York: Continuum Books, 2002.

Deleuze, Gilles. Différence et Répétition. Paris : PUF, 1968.

Deleuze, Gilles. Empirisme et Subjectivité. Paris : PUF, [1953] 1993.

Deleuze, Gilles. L'Image-Temps. Paris : Minuit, 1985.

Deleuze, Gilles. Pourparlers. Paris: Minuit, 1990.

63. Gilles Deleuze, Pourparlers, 172 (sublinhados nossos).

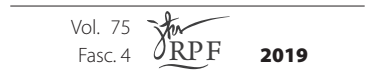


Deleuze, Gilles. Proust et les Signes. Paris : Quadrige/PUF, [1964] 1998.

Deleuze, Gilles. "Qu'est-ce que l'Acte de Création ?" <https://www.youtube.com/ watch?v=2OyuMJMrCRw > acedido a 23 de novembro de 2019.

Deleuze, Gilles e Guattari, Félix. Qu'est-ce que la Philosophie ?. Paris : Minuit, 1991.

Deleuze, Gilles e Parnet, Claire. Dialogues. Paris: Flammarion, 1977.

Kac, Eduardo < https://www.ekac.org/kac2.html>.

Kemp, Martin, Visualizatios. The Nature Book of Art and Science, Oxford/New York: Oxford University Press, 2000.

Kessler, Rob <https://www.robkesseler.co.uk/>.

Le Lionnais, François, "Raymont Queneau et l'Amalgame des Mathématiques et de la Littérature", in Atlas de Littérature Potentielle, editado por Oulipo, Paris : Gallimard, 1981.

Lyons, Lucy <https://www.lucylyons.org/>.

Marks, John. Deleuze and Science, Edinburg: Edinburg University Press, 2006.

Menezes, Marta de <https://martademenezes.com/portfolio/projects/>.

Moura, Leonel (ed.), Inside. Arte e Ciência, Lisboa: LxXL, 2009.

Pombo Nabais, Catarina. Gilles Deleuze : Philosophie et Littérature, Paris : Harmattan, 2013.

Pombo, Olga (ed). Image in Science and Art. Lisboa: Fim de Século, 2017.

John Protevi, Life, War, Earth: Deleuze and the Sciences, Minnesota: Minnesota University Press, 2013.

Salgado, Pedro < https://www.fc.up.pt/Ilustracao_Cientifica/corpo-docente/pedro-salgado/>.

Salgado, Pedro "Field sketching and scientific illustration: drawing to understand nature and drawing to explain". In Image in Science and Art, editado por Olga Pombo, 221-231. Lisboa: Fim de Século, 2017.

Science, Art, Philosophy Lab (Sap-Lab) <http://sap-lab.org/>.

Sokal, Alan e Bricmont, Jean. Imposturas Intelectuais. Lisboa : Gradiva, 1999.

Turk, Hervig <https://anti-utopias.com/artist/herwig-turk/>.

Zourabichvili, François. Le Vocabulaire de Deleuze. Paris : Ellipses, 2003. 
